\title{
Synergy between Growth Factors and Transmitters Required for Catecholamine Differentiation in Brain Neurons
}

\author{
Xinyu Du and Lorraine lacovitti \\ Institute of Neuroscience, Department of Neurology, Hahnemann University, Philadelphia, Pennsylvania 19102
}

The phenotypically plastic neurons of the embryonic mouse striatum were used to explore mechanisms of catecholamine differentiation in culture. De novo transcription and translation of the CA biosynthetic enzyme, tyrosine hydroxylase (TH), was induced in striatal neurons exposed, simultaneously or sequentially, to the growth factor, acidic fibroblast growth factor (aFGF) and a catecholamine. Although dopamine was the most potent aFGF partner $\left(E D_{50}\right.$ $=4 \mu \mathrm{M}$ ), a number of substances, including dopamine (D1) receptor agonists, $\beta$-adrenoceptor agonists, and dopamine uptake inhibitors also trigger TH induction when accompanied by aFGF. However, since none of the receptor antagonists nor transport blockers tested could inhibit dopamine's action, the mechanism remains obscure. Structure-activity analysis suggests that effective aFGF partners all contain an amine group separated from a catechol nucleus by two carbons. Thus, TH expression can be novelly induced by the synergistic interaction of aFGF, and to a lesser extent basic FGF, and a variety of CA-containing partner molecules. We speculate that a similar association between growth factor and transmitter may be required in development for the differentiation of a CA phenotype in brain neurons.

[Key words: fibroblast growth factor, dopamine, tyrosine hydroxylase, striatal neurons, t/ssue culture, catecholamine differentiation]

Although the differentiation of the nervous system into neurons of specific biochemical class remains an elusory process, clues as to the underlying mechanisms are now emerging. In the PNS, studies have indicated that individual growth factors act as critical determinants of transmitter type (Saadat and Thoenen, 1986; Adler, 1989; Wong and Kessler, 1989; Yamamori et al., 1989; Rohrer, 1992; Howard and Gershon, 1993; Rao and Landis, 1993). In the brain, however, the initiation of neurotransmitterspecific genes appears to involve more complex mechanisms, requiring the obligatory interactions of multiple signal molecules (Du et al., 1994). Although growth factors play a prominent role, their cooperation with auxiliary agents is essential. Thus, exposure in culture both to the growth factor, aFGF, and an additional unidentified muscle agent (demonstrated not to be hepa-

\footnotetext{
Received Jan. 17, 1995; revised Mar. 16, 1995; accepted Mar. 21, 1995.

We are grateful to Ms. Natalie Stull for her excellent technical assistance in all aspects of the project. This work was supported by NIH NS24204 and a research gift from Amgen, Inc.

Correspondence should be addressed to Lorraine Iacovitti, Institute of Neuroscience, Department of Neurology, Hahnemann University, Broad and Vine Streets, Philadelphia, PA 19102.

Copyright $\odot 1995$ Society for Neuroscience $\quad 0270-6474 / 95 / 155420-08 \$ 05.00 / 0$
}

rin) is necessary to trigger novel expression of the normally quiescent TH gene in non-CA neurons of the striatum (Du et al., 1994). Whether aFGF and its partner substance are also responsible for signaling the constitutive expression of TH in CA neurons is not yet clear. Consistent with the latter notion, however, is the emergence of $\mathrm{TH}$ in differentiating $\mathrm{CA}$ neurons (Specht et al., 1981) simultaneously with the appearance of aFGF in the developing brainstem (Ferrari et al., 1989; Engele and Bohn, 1991; Fu et al., 1991; Schnürch and Risau, 1991; Wilcox and Unnerstall, 1991; Nurcombe et al., 1993). The possibility is thus raised that CA neurons harbor or have local access to all of the agents necessary for their own biochemical differentiation, including, aFGF and its partner molecule. Supporting this proposition is our preliminary finding that an extract of CA neurons, derived from adult substantia nigra (SN) tissue, is indeed capable of inducing $\mathrm{TH}$ expression in cultured striatal neurons. SN neurons, in addition to their supply of endogenous aFGF (Engele and Bohn, 1991; Schnürch and Risau, 1991; Wilcox and Unnerstall, 1991; Nurcombe et al., 1993), also contain high concentrations of C.A neurotransmitters, conceivably important in aFGF activation. Since biogenic amines are thought to subserve a number of critical functions in fetal development (Coyle, 1972; Lauder, 1988; Mattson, 1988; Meier et al., 1991), their potential participation in the CA differentiation process and probable mechanism of action were explored here. We will show that induction of the CA-specific gene, $\mathrm{TH}$, is mediated by a novel mechanism which requires the convergent actions of both aFGF and, paradoxically, the enzyme's catalytic end products, the CAs. That neurotransmitters might work coordinately with growth factors to initiate (Iacovitti et al., 1989; Iacovitti, 1991) and subsequently modulate (DeVitry et al., 1991; Iacovitti et al., 1992; Louis et al., 1993; Magal et al., 1993; Iacovitti, 1994) their own synthesis could provide an exciting new model for autoregulation during development and thereafter. The possible mechanisms through which various CAs might achieve these effects is discussed.

\section{Materials and Methods}

Tissue culture. Pregnant Swiss white mice were purchased from Taconic Lab Animals at $9 \mathrm{~d}$ gestation $\pm 12 \mathrm{hr}$ fertilization day $=$ embryonic day (E) 0 . Pregnant dams were anesthetized with pentobarbital on gestational day 13 and the embryos removed. The developing striatum was isolated from the remainder of the brain as described previously (Iacovitti et al., 1989; Du et al., 1994). After removal of the meninges, tissue was minced $(0.5 \mathrm{~mm}$ pieces $)$ and incubated in $\mathrm{Ca}^{2+} / \mathrm{Mg}^{2+}-$ free Hanks' balanced salt solution (CMF-HBSS) for $8 \mathrm{~min}$ at $37^{\circ} \mathrm{C}$ in a clinical rotator $(40 \mathrm{rpm})$. The incubation mixture was replaced with a $0.01 \%$ trypsin solution (in CMF-HBSS), and incubated for an additional $8 \mathrm{~min}$, rinsed twice in Leibovitz's medium (L-15), and placed in culture medium containing Dulbecco's minimum essential medium, $10 \%$ fetal calf serum (Irvine Scientific) glucose $(6 \mathrm{mg} / \mathrm{ml})$, glutamine $(204 \mu \mathrm{g} /$ 
$\mathrm{ml})$, and penicillin/streptomycin $(100 \mathrm{U} / \mathrm{ml})$. Cells were dissociated by trituration through a reduced bore glass pipette and plated onto glass Lab Tek culture dishes coated with polymerized polyornithine (precoated for $48 \mathrm{hr}$ at room temperature at a concentration of $0.1 \mathrm{mg} / \mathrm{ml}$ in $15 \mathrm{~mm}$ borate buffer, $\mathrm{pH} \mathrm{8.4)}$ and then rinsed with water and air dried 2-4 min. The cellular plating density was approximately $0.5-1 \times$ $10^{6}$ cells/dish. After a $1 \mathrm{~d}$ stabilization period in standard media, cultures were incubated overnight in defined media (Bottenstein and Sato, 1979) containing test reagents. The following day cultures were fixed and processed for the immunocytochemical localization of TH unless otherwise stated.

TH immunocytochemistry. Cultures were fixed in $4 \%$ paraformalde hyde in $0.1 \mathrm{M}$ phosphate buffer ( $\mathrm{pH} 7.4$ ) and processed with antibodies to TH (1:5000 dilution, kind gift of Dr. T. H. Joh, New York, NY) using the immunoperoxidase/ABC method of staining (Elite Vectakit). Except where stated otherwise, TH induction was determined by counting positively stained cells in $50 \%$ off the microscopic fields on the culture dish. This was accomplished with the aid of an eyepiece reticule used at a $10 \times$ magnification. To eliminate the possibility that brainstem noradrenergic neurons were inadvertently included in dissected brain tissue, cultures of midbrain neurons were screened with antibodies to the noradrenergic enzyme dopamine- $\beta$-hydroxylase. At no time were stained midbrain neurons observed in these cultures.

Pharmacological studies. E13 mouse striatal neurons were established in culture as described previously (Iacovitti et al., 1989). Cultures were stabilized $1 \mathrm{~d}$ prior to the addition of various reagents to the media (see Table 2 for listing). To examine the role of dopamine receptors (D1-D5) and adrenoceptors ( $\alpha$ and $\beta$ ) in TH induction, cultures were simultaneously treated with test compounds (at a concentration range of 1-200 $\mu \mathrm{m})$ and aFGF $(10 \mathrm{ng} / \mathrm{ml})$. In other cultures, we evaluated the ability of test compounds (i.e., receptor antagonists or transport inhibitors; $1-200 \mu \mathrm{M})$ to inhibit TH induced by aFGF $(10 \mathrm{ng} / \mathrm{ml})+\mathrm{CA}$ (either DA at $10 \mu \mathrm{M}$ or NE at $50-100 \mu \mathrm{M}$ ). Culture media was supplemented with test reagents $2 \mathrm{hr}$ prior to the addition of TH-inducing agents. The day after the various treatments, all cultures were fixed in $4 \%$ paraformaldehyde, immunocytochemically stained for the localization of TH, and scored for TH induction as described previously (Iacovitti et al., 1989). The results are expressed as the percentage of total neurons which stained positively with antibodies to $\mathrm{TH}$.

Statistical analysis. Data were statistically analyzed by one-way analysis of variance. When $P<0.05$, then the $F$ test was followed by the two-tailed Student's $t$ test to compare the statistical significance between control and experimental groups. Differences were considered significant only when the $P$ value was less than 0.05 .

Chemical reagents. All transmitter-related compounds, cyclohexamide, and $\alpha$-amanitin were purchased from Sigma Chemical (St. Louis, MO). All receptor agonist and antagonists were purchased from RBI (Natick, MA). Growth factors were acquired from the following sources: aFGF, bFGF, and FGF-7 were kind gifts of Amgen; FGF-6 was kindly supplied by Dr. F. Coulier (Marseille, France); NGF was a gift from Dr. E. M. Johnson (St. Louis, MO); CNTF was kindly supplied by Scios Nova Inc.; EGF, LIF, ILl and TGFB were purchased from R and D Systems. All reagents used in culture were ohtained from GIB$\mathrm{CO}$.

\section{Results}

\section{Induction of TH by aFGF and CAs}

The phenotypically plastic neurons of the E13 mouse striatum were chosen as the model system for these studies since their neurotransmitter profile can be permanently altered by exposure to differentiative cues in culture (Iacovitti et al., 1989; Iacovitti, 1991; Du et al., 1994). As part of our initial screening, we tested the capacity for a variety of neurotransmitters and related compounds to induce $\mathrm{TH}$ in striatal neurons when incubated alone or in combination with aFGF. As seen in Table 1, administration of neurotransmitter substances or aFGF alone had no apparent effect on $\mathrm{TH}$ expression. In contrast, the combined treatment of aFGF with transmitters, specifically CA transmitters, resulted in a striking induction in $\mathrm{TH}$ in striatal neurons. Dopamine was particularly effective as an aFGF partner $\left(\mathrm{ED}_{50}=4 \mu \mathrm{M}\right)$, initiating the expression of $\mathrm{TH}$ in the majority of cultured striatal neurons (Fig. 1). However, dose-response studies (Fig. 2) re-
Table 1. Effects of various neurotransmitter-related substances on TH induction in striatal neurons grown in the absence or presence of aFGF in culture.

\begin{tabular}{lllr} 
& \multicolumn{2}{l}{$\begin{array}{l}\text { Percentage TH- } \\
\text { positive neurons }\end{array}$} & \\
\cline { 2 - 3 } Treatment & $\begin{array}{l}\text { Without } \\
\text { aFGF }\end{array}$ & $\begin{array}{l}\text { With } \\
\text { aFGF }\end{array}$ & FD $_{50}^{*}$ \\
\hline Control & ND & $<10$ & \\
L Dopa & ND & $38 \pm 5$ & $50 \mu \mathrm{M}$ \\
Dopamine & ND & $57 \pm 5$ & $4 \mu \mathrm{M}$ \\
Norepinephrine & ND & $43 \pm 6$ & $25 \mu \mathrm{M}$ \\
Epinephrine & ND & $37 \pm 5$ & $85 \mu \mathrm{M}$ \\
Carbacol & ND & $<5$ & \\
Nicotine & ND & $<5$ & \\
Serotonin & ND & $<5$ & \\
GABA & ND & $<5$ & \\
Glutamate & ND & $<5$ &
\end{tabular}

E13 mouse striatal neurons were established in culture as described previously (Iacovitti et al., 1989). Cultures were stabilized one day prior to the addition of various neurotransmitter substances to the media (at a concentration range of $1-800 \mu \mathrm{M}$ ). Some of the cultures were simultaneously treated with exogenous aFGF $(10 \mathrm{ng} / \mathrm{ml})$. The following day, all cultures were fixed in $4 \%$ paraformaldehyde, immunocytochemically stained for the localization of $\mathrm{TH}$, and scored for TH induction as described previously (Iacovitti et al., 1989). The results are expressed as the percentage of total neurons which stained positively with antibodies to TH. Each value represents the mean \pm the SD for triplicate cultures in 2 separate platings.

ND, not detectable.

* $\mathrm{ED}_{50}$ values were calculated for cultures co-treated with aFGF $(10 \mathrm{ng} / \mathrm{ml})$ and $1-200 \mu \mathrm{M}$ neurotransmitter.

vealed that other CA-containing compounds, such as, L-dopa, norepinephrine and epinephrine were also effective, albeit at higher concentrations $\left(\mathrm{ED}_{50}=25-85 \mu \mathrm{M}\right)$. The role of catecholamines in this effect may be important for explaining the low level TH induction sometimes observed when aFGF was added to the media in the absence of exogenous partner molecules ( $\mathrm{Du}$ et al., 1994). In all cases of basal TH induction, scattered THimmunoreactive neurons were observed, even in control (untreated) cultures. It is conceivable that the presence in some platings of these spurious TH neurons resulted in the production of low levels of endogenous L-dopa or dopamine which then partially induced TH expression in other neurons when aFGF was added exogenously.

In contrast to CAs, when cultures of striatal neurons were incubated with various concentrations of monoamine precursors or their metabolites $(1.0 \mu \mathrm{M}$ to $200 \mu \mathrm{M}$ of tyrosine, tyramine, homovanillic acid and 3,4-dihydroxyphenylacetic acid) alone or in combination with aFGF $(10 \mathrm{ng} / \mathrm{ml})$, no $\mathrm{TH}$ induction was observed (data not shown).

\section{Studies on the mechanism of CA action}

We next investigated whether CAs mediated their cellular effects through either dopaminergic/adrenergic membrane receptors or by direct uptake into the cell via transporter mediated systems. Summarized in Table 2 is a list of receptor agonist and antagonist compounds and transport blockers which were tested in an attempt to either stimulate or inhibit $\mathrm{CA}$ assisted $\mathrm{TH}$ induction by aFGF. All reagents were first evaluated for $\mathrm{TH}$-inducing capacity when administered alone. In no case was TH induced by treatment solely with a receptor agonist, antagonist or uptake blocker (data not shown). To begin to understand the role of dopamine receptors (D1-D5) and/or adrenoceptors ( $\alpha$ and $\beta$ ) in 

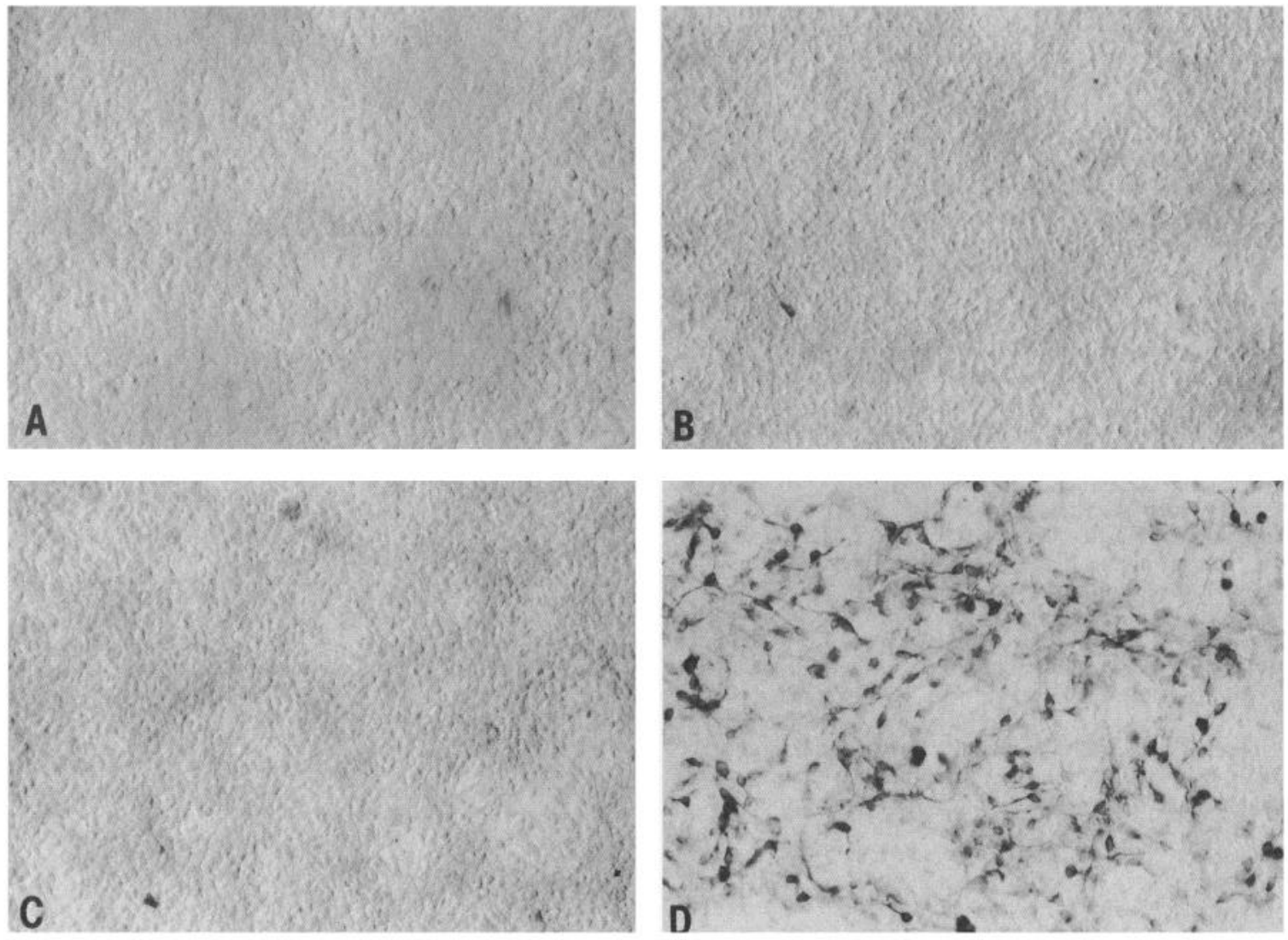

Figure 1. Immunocytochemical localization of TH in cultured striatal neurons. Neurons were established in culture (Iacovitti et al., 1989; Iacovitti, $1991) 1 \mathrm{~d}$ prior to incubation in control media $(A)$ or in media supplemented with $10 \mathrm{ng} / \mathrm{ml} \mathrm{aFGF}(B), 10 \mu \mathrm{M} \mathrm{dopamine}(C)$; or $10 \mathrm{ng} / \mathrm{ml} \mathrm{aFGF}$ $+10 \mu \mathrm{M}$ dopamine $(D)$. The following day, cultures were fixed and TH was immunocytochemically localized. Note that dopamine, in collaboration with aFGF, produced a striking induction of TH in many of cultured striatal neurons.

mediating TH induction, cultures were simultaneously treated with a maximal inducing dose of $\mathrm{aFGF}(10 \mathrm{ng} / \mathrm{ml})$ and selective CA receptor agonists/antagonists (see Table 2 listing) at a concentration range of 1-200 $\mu \mathrm{M}$. We found that the D1/D5 receptor agonist SKF 38393, in all rotameric conformations $(+,-, \pm)$, could successfully substitute for dopamine, inducing $\mathrm{TH}$ expression in $60 \%$ of those striatal neurons simultaneously treated with aFGF. However, pre- and cotreatment with known D1 receptor antagonists (1-200 $\mu \mathrm{M})$ were unable to block this effect. Neither SCH 23390, apomorphine, haloperidol could inhibit TH induced by aFGF $(10 \mathrm{ng} / \mathrm{ml})+$ dopamine $(10 \mu \mathrm{M})$ or SKF 38393 (10 $\mu \mathrm{M}$; data not shown). Other dopamine receptor (D2, D3, D4) agonists and antagonists neither stimulated nor inhibited $\mathrm{TH}$ expression in striatal neurons. We next tested the potential role of classic adrenergic receptors in TH induction. The $\beta$-adrenergic receptor agonist, isoproterenol, similar to NE (reported above), was a potent aFGF partner, inducing TH immunoreactivity in the majority of striatal neurons (Table 2). Again, however, the $\beta$-adrenergic antagonist propranolol was incapable of preventing induction by $\mathrm{aFGF}$ and $\mathrm{NE}$ or Isoproterenol.

Since it is possible that CAs do not work at the membrane, but rather exert their effects intracellularly following uptake via a neurotransport system, we attempted with known DA uptake blockers (mazindol, nomifensine, etc.) or GABA uptake blockers (nipecotic acid; 1-amino-1-cyclohexane carboxylic acid, ACCA) to inhibit TH induction. As we had seen with the receptor antagonists, no uptake compound tested (even at a 20- fold excess concentration; $400 \times$ the $\mathrm{IC}_{50}$ ) was able to block induction by aFGF and dopamine (Table 2). Moreover, selective inhibitors of GABA uptake did not prevent TH induction, suggesting that the GABA transporter is not responsible for taking up CAs in these experiments. Likewise dopamine transport inhibitors could not block, though several (mazindol, GYKI 52895) paradoxically mimicked the effects of dopamine, producing $40 \% \mathrm{TH}$ induction when co-incubated with aFGF. Moreover, in the case of mazindol, the level of induction could be further increased by the addition of dopamine as well as aFGF. Although it is possible that mazindol, by blocking reuptake of dopamine, increases extracellular levels of transmitter sufficiently to partner aFGF, this does not explain its ability to enhance $\mathrm{TH}$ induction when co-incubated with a maximally inducing dose of dopamine. The additive effects of mazindol and dopamine imply that both agents may partner aFGF but their mechanisms of action may differ.

\section{CA activating effect is maximal for aFGF compared to other growth factors}

In addition to aFGF, ongoing studies (Du et al., 1995) suggest that other dopamine differentiation factors, such as brain-derived growth factor (BDNF) (but not glial-derived growth factor), may also possess some ability to induce $\mathrm{TH}$ expression in the presence of partner molecules (30\% induction). We therefore tested whether other neural growth factors could initiate $\mathrm{TH}$ when partnered by CA. Striatal cultures were incubated overnight in media 


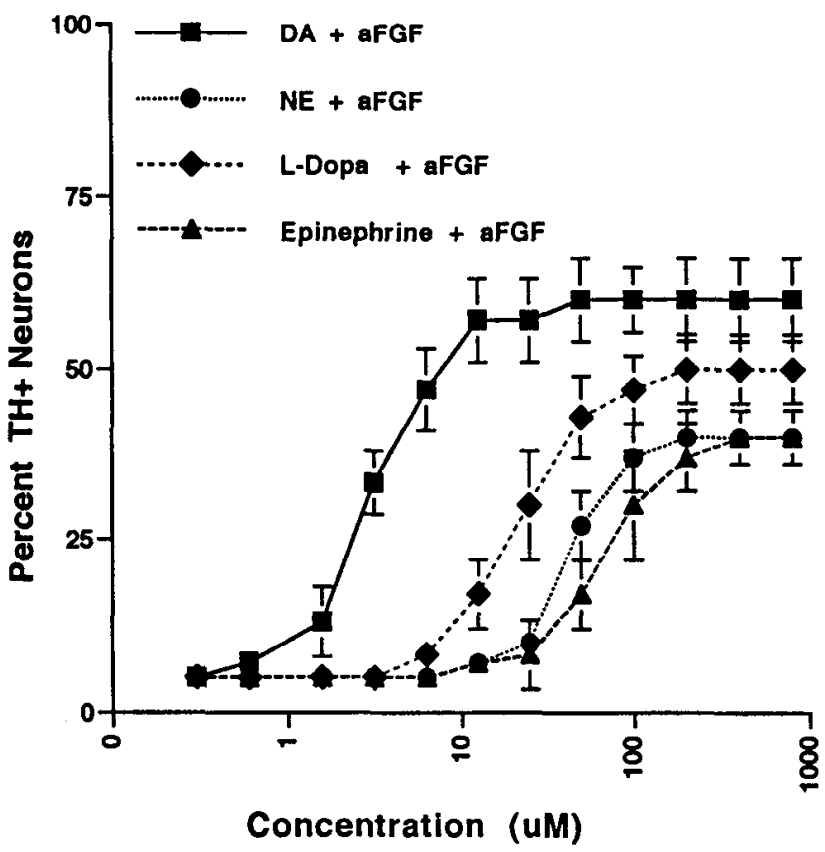

Figure 2. Dose dependency of the effect of catecholamines on aFGFinduced TH expression in E 13 cultured striatal neurons. One day after plating, cultures were fed media supplemented with $10 \mathrm{ng} / \mathrm{ml} \mathrm{aFGF}$ and various concentrations $(0.3-800 \mu \mathrm{M})$ of dopamine (square), norepinephrine (NE) (circle), L-dopa (diamond), or epinephrine (triangle). The following day, cultures were fixed and evaluated for TH induction. Values are expressed as the percentage of TH positive neurons in the culture. Each value represents the mean \pm SD of four determinations for two separate platings.

containing aFGF, bFGF, FGF-6, FGF-7, epidermal growth factor (EGF), NGF, ciliary neurotrophic factor (CNTF), leukemia inhibitory factor (LIF), transforming growth factor $\beta$ (TGF $\beta$ ), or interleukin 1 (IL1) alone or in combination with $10 \mu \mathrm{M}$ dopamine. The following day $\mathrm{TH}$ induction was evaluated immunocytochemically. Of the growth factors tested, only aFGF, and to a lesser extent, its isoform basic FGF (bFGF) could induce TH expression when dopamine was included in the incubation media (Fig. 3). Although the maximum level of induction was lower for bFGF than aFGF, both growth factors generated nearly identical time courses when incubated with dopamine: $\mathrm{TH}$ expression was first evident at $6 \mathrm{hr}$, peaked by $12 \mathrm{hr}$ and remained elevated even $108 \mathrm{hr}$ following treatment (Fig. 3).

\section{Synergy does not require co-incubation of aFGF and CAs}

In an attempt to localize the synergy between aFGF and its partner molecule, TH induction was compared after the simultaneous or sequential incubation of inducing agents. TH induction was compared in cultures incubated simultaneously with aFGF $(10 \mathrm{ng} / \mathrm{ml})$ and $( \pm)$ SKF $38393(100 \mu \mathrm{M})$ and those which received successive treatments with the individual reagents. In the former group, both reagents were added together for $0.25-4.0$ $\mathrm{hr}$, media was then removed, cultures were rinsed twice for 5 min each and reincubated for the remaining time in defined media (which had not been supplemented with added agents). In the latter group, cultures were treated for various periods of time $(0.25-4.0 \mathrm{hr})$ with aFGF or $( \pm)$ SKF 38393 , rinsed as above and then re-incubated with the reciprocal agent. The next day, cultures were fixed and stained with TH antibodies. After sequential treatment, induction was observed regardless of whether aFGF was added first and then replaced with ( \pm )SKF 38393 or vice versa (data not shown). However, aFGF required a longer exposure time (4 hr) than did ( \pm )SKF 38393 (30 min) for initiating the effect. When both reagents were added simultaneously to the culture, increased TH expression was also observed within $4 \mathrm{hr}$ of cotreatment. The fact that both aFGF and the dopamine receptor agonist need not be incubated together suggests that the effect occurs independent of conformational changes resulting from their direct molecular interaction. Instead, it appears that convergence of aFGF and its partner occurs inside the cell, possibly along their intracellular signaling pathways.

\section{De novo transcription and translation are required for $\mathrm{TH}$ induction by aFGF and dopamine}

As suggested by our earlier studies (Iacovitti et al., 1989; Iacovitti, 1991), the induced appearance of immunoreactive TH in striatal neurons, required both de novo transcription and translation. Thus, inhibition of protein synthesis with cyclohexamide decreased in a dose-dependent manner the number of $\mathrm{TH}$ immunoreactive neurons elicited by dopamine and aFGF treatment; inhibiting over $90 \%$ of TH induction at the maximum dose tested $(1000 \mathrm{ng} / \mathrm{ml})$ (Fig. 4). Preincubation of neurons with the RNA polymerase inhibitor $\alpha$-amanitin, at a dose range $(4 \mu \mathrm{g} /$ ml) which totally inhibits RNA polymerase II (Roeder, 1976), reduced by more than $50 \%$ the number of $\mathrm{TH}$ immunoreactive neurons (Fig. 4). Higher concentrations $(400 \mu \mathrm{g} / \mathrm{ml})$ of amanitin which inhibit RNA polymerase III as well (Stott, 1991), prevented $90 \%$ of the usual induction of TH.

\section{Discussion}

The results of these studies suggest that, in mammalian brain, as in simpler invertebrate systems (Karin, 1989; Foulkes et al., 1991; Lamb and McKnight, 1991; Bowers, 1994), gene expression is controlled by the synergistic and competitive interactions of several regulatory factors. Thus, the growth factor aFGF, and to a lesser extent bFGF, working in concert with a partner molecule, shown here to be a CA neurotransmitter, will trigger the novel expression of $\mathrm{TH}$ in non-CA neurons. This expression requires both de novo transcription of the $\mathrm{TH}$ gene and translation of the mRNA into newly synthesized protein.

\section{Mechanism of TH induction}

The mechanisms through which the cultured striatal neuron achieves these actions remain elusory. It is presumed but not yet proven that aFGF exerts its effects by binding to one or more of the four high affinity tyrosine kinase-linked membrane receptors (Donne et al., 1991). CAs, on the other hand, may mediate their cellular actions through several routes. First, CA membrane receptors, including dopamine (D1/D2) receptors (Maus et al., 1989; Premont et al., 1983) as well as $\alpha$ - (Weiss et al., 1987) and $\beta$ - (Van Vliet et al., 1991) adrenoceptors present on cultured striatal neurons might activate second messenger systems to bring about TH induction. Indeed, in our studies, agonists of the D1/D5 dopamine receptor and the $\beta$-adrenergic receptor mimicked the TH inductive effects of dopamine and NE, respectively. However, the fact that specific antagonists of these sites did not inhibit their action (even in concentrations $400 \times$ the $\mathrm{IC}_{50}$ ) suggests that these receptors are not the mediators of TH induction.

Although there is no evidence for the existence of a dopamine transporter (Shimada et al., 1992; Cerruti et al., 1993; Grant et al., 1994) on GABAergic neurons of the adult striatum, we none- 
Table 2. Effects of various receptor agonists, antagonists, or uptake inhibitors on TH induction.

\begin{tabular}{|c|c|c|c|c|}
\hline \multirow[b]{2}{*}{ Treatment } & \multirow[b]{2}{*}{ Site of action } & \multirow[b]{2}{*}{ Main action } & \multicolumn{2}{|c|}{ TH induction } \\
\hline & & & $+\mathrm{aFGF} *$ & $+\mathrm{aFGF}+\mathrm{DA}^{* *}$ \\
\hline \multicolumn{5}{|l|}{ Dopamine receptors } \\
\hline $\mathrm{R}(+)$ SKF 38393 & D1/D5 & agonist & +++ & ND \\
\hline S (-) SKF 38393 & D1/D5 & agonist & +++ & ND \\
\hline RS ( \pm ) SKF 38393 & D1/D5 & agonist & +++ & ND \\
\hline $\mathrm{R}(+)$ 6-bromoAPB & D1/D5 & agonist & + & ND \\
\hline $\mathrm{R}(+) \mathrm{SCH} 23390$ & D1/D5 & antagonist & - & +++ \\
\hline Quinpirole & $\mathrm{D} 2 / \mathrm{D} 3 / \mathrm{D} 4$ & agonist & - & ND \\
\hline Spiperone & $\mathrm{D} 2 / \mathrm{D} 3 / \mathrm{D} 4$ & antagonist & - & +++ \\
\hline Apomorphine & $\mathrm{D} 1 / \mathrm{D} 2$ & agonist & + & +++ \\
\hline Halperidol & D1/D2 & antagonist & ND & +++ \\
\hline SCH-23390 + Spiperone & $\mathrm{D} 1 / \mathrm{D} 2 / \mathrm{D} 3 / \mathrm{D} 4$ & antagonist & $\mathrm{ND}$ & +++ \\
\hline & & & $+\mathrm{aFGF}$ & $+\mathrm{aFGF}+\mathrm{NE}^{\prime}$ \\
\hline \multicolumn{5}{|l|}{ Adrenoceptors } \\
\hline Phenylephrine & alpha 1 & agonist & - & ND \\
\hline Prazosin & alpha 1 & antagonist & ND & ++ \\
\hline Clonidine & alpha 2 & agonist & - & ND \\
\hline Yohimbine & alpha 2 & antagonist & - & ++ \\
\hline Yohimbine + Prazosin & alpha $1 / 2$ & antagonist & ND & ++ \\
\hline Isoproterenol & beta & agonist & ++ & ND \\
\hline Propranolol & beta & antagonist & - & ++ \\
\hline & & & $+\mathrm{aFGF}$ & $+\mathrm{aFGF}+\mathrm{DA}$ \\
\hline \multicolumn{5}{|l|}{ Uptake sites } \\
\hline Mazindol & DA transporter & blockade & ++ & ++++ \\
\hline Nomifensine & DA transporter & blockade & - & +++ \\
\hline GYKI 52895 & DA transporter & blockade & ++ & +++ \\
\hline GBR-12935 & DA transporter & blockade & + & +++ \\
\hline WIN 35,428 & DA transporter & blockade & - & +++ \\
\hline Indatraline & $\mathrm{D} \Lambda, \mathrm{NE}, 5-\mathrm{HT}$ & blockade & - & +++ \\
\hline $\mathrm{ACCA}$ & GABA transporter & blockade & - & +++ \\
\hline RS $( \pm)$ Nipecotic acid & GABA transporter & blockade & - & +++ \\
\hline
\end{tabular}

E13 mouse striatal neurons were established in culture as described previously (Iacovitti et al., 1989). Cultures stabilized one day prior to the addition of various reagents to the media. The ability of compounds to substitute for CA in TH induction was evaluated by co-treatment of cultures with $1-200 \mu \mathrm{M}$ of the receptor agonist, antagonist, or uptake inhibitor and $10 \mathrm{ng} / \mathrm{ml}$ of aFGF (left column). The capacity to block TH induction by aFGF $+\mathrm{CA}$ (either dopamine [DA] at $10 \mu \mathrm{M}$ or NE at $50-100 \mu \mathrm{M}$ ) was assessed by pretreatment of the cultures for $2 \mathrm{hr}$ with the test compound before the further addition of aFGF $(10 \mathrm{ng} / \mathrm{ml})+$ the appropriate $\mathrm{CA}(10 \mu \mathrm{M})$ to the media (right column). On the day following the various treatments, all cultures were fixed in $4 \%$ paraformaldehyde, immunocytochemically stained for the localization of $\mathrm{TH}$, and scored for $\mathrm{TH}$ induction as described previously (lacovitti et al., 1989). The results are expressed as the percentage of total neurons which stained positively with antibodies to $\mathrm{TH}$. Each + represents approximately $20 \% \mathrm{TH}$ immunoreactive neurons (i.e., $+++=60 \%$ ); - , no induction in $\mathrm{TH}$ expression over control levels; $\mathrm{ND}$, not determined. Controls: * $\mathrm{aFGF}(10 \mathrm{ng} / \mathrm{ml})$ only yields no $\mathrm{TH}$ induction; ** aFGF $(10 \mathrm{ng} / \mathrm{ml})+\mathrm{DA}(10 \mu \mathrm{M})$ yields $+++\mathrm{TH}$ induction; ! aFGF $(10 \mathrm{ng} / \mathrm{ml})+\mathrm{NE}(50 \mu \mathrm{M})$ yields $++\mathrm{TH}$ induction.

theless tested whether dopamine was gaining access to the cell via an uptake mechanism. When agents known for their ability to block dopamine transporter activity were tested, they did not prevent the induction of TH by aFGF and dopamine. In fact, several dopamine uptake inhibitors were instead inducers of $\mathrm{TH}$ when co-incubated with growth factor. This group of apparently disparate aFGF partners (D1/D5 agonists, $\beta$-adrcnergic agonists, dopamine uptake inhibitors) share several distinguishing biochemical features; all members contain an amine group separated from a catechol nucleus by two carbons. The fact that these chemical traits are virtually identical to those required for optimal uptake by the dopamine transporter (Meiergerd and Schenk, 1994) raises several possibilities. First, it is conceivable that embryonic striatal neurons contain the dopamine neurotransporter in addition to the usual GABA transporter (Radian et al., 1990) but expression of the former is lost by adulthood. Precedent for the coexistence of GABA and DA transporters on the same cell has indeed been reported previously (Bonanno and Raiteri, 1987). Alternatively, it is possible that the embryonic GABA transporter possesses recognition and/or translocation sites which are less discriminating than the adult, permitting uptake of dopamine and other related catechols. In view of the fact that it is now believed that the gene family of neurotransporters is far larger than originally suspected (i.e., "orphan" transporters with no known function have been identified) (Uhl, 1987), an entirely new neurotransporter may account for our results. Regardless of whether striatal neurons possess an embryonic form of the DA or GABA transporter or a new transporter, our results make clear that this site can not be blocked by the usual inhibitors of dopamine or GABA uptake. 


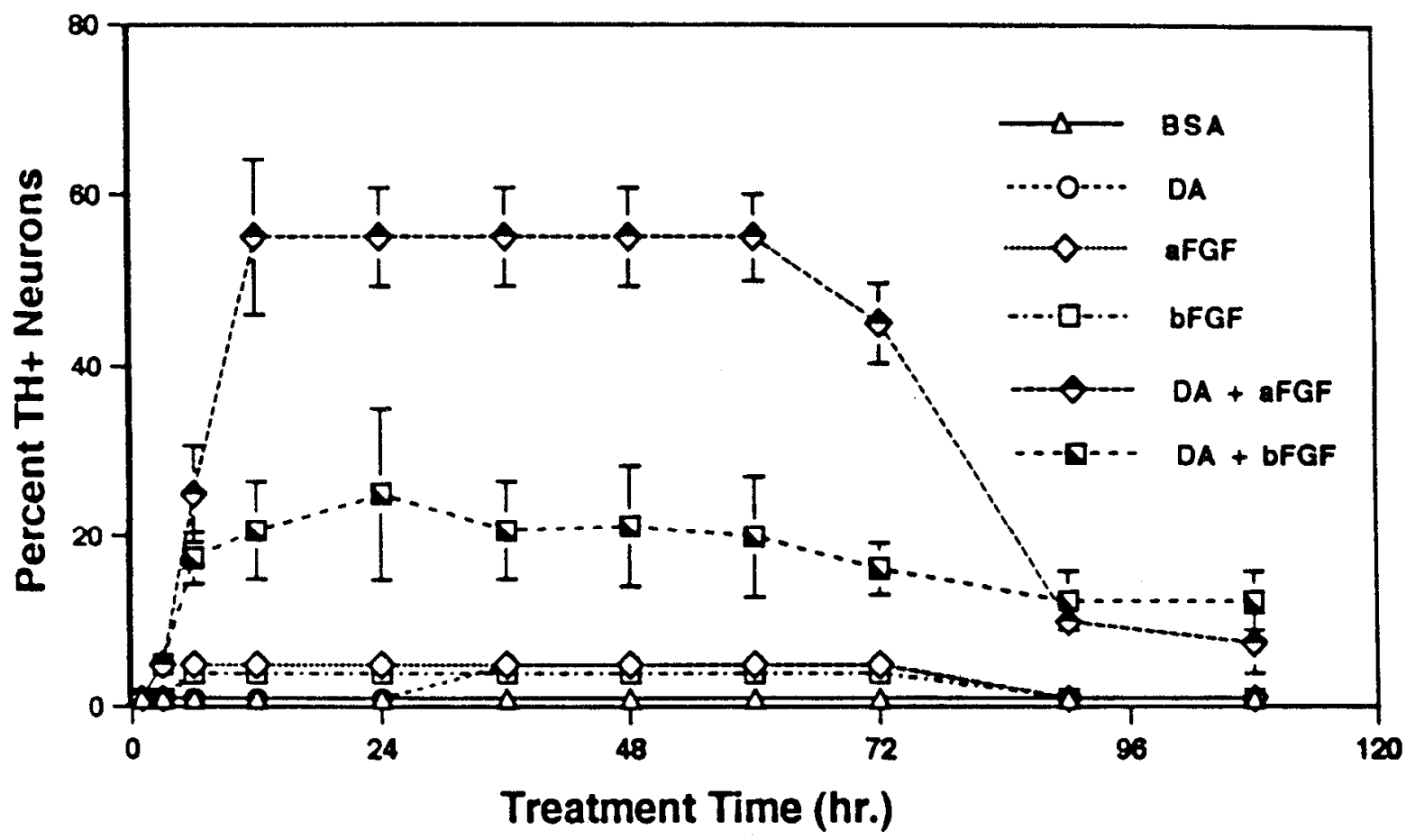

Figure 3. Time course of TH expression in striatal neurons incubated in media containing $1 \mathrm{mg} / \mathrm{ml}$ of BSA (triargle), $10 \mu \mathrm{M}$ dopamine $(D A$, circle), $10 \mathrm{ng} / \mathrm{ml}$ aFGF (open diamond), $10 \mathrm{ng} / \mathrm{ml} \mathrm{bFGF}$ (square), DA + aFGF (shaded diamond), DA + bFGF (shaded square). Cultures were fixed at various time intervals up to $108 \mathrm{hr}$ and $\mathrm{TH}$ induction was evaluated immunocytochemically. Values are expressed as the percentage of TH positive neurons in the culture. Each value represents the mean $\pm \mathrm{SD}$ of three to six determinations for two separate platings.

Finally, we can not overlook the possibility that, since $\mathrm{TH}$ induction is not inhibited by classic receptor antagonists or transport blockers and can be initiated by both $D$ and $L$ forms of the receptor agonist SKF 38393, dopamine utilizes a novel mechanism to mediate its effects on striatal neurons. Since the byproducts of lipid peroxidation are known to increase gene transcription and stimulate biochemical differentiation in a variety of developing tissues (Allen, 1991), one intriguing possibility is that catechols induce $\mathrm{TH}$ by increasing lipid peroxidation of the cell membrane. Resolution of these issues awaits further investigation.

\section{Relevance to CA differentiation}

Whether these in vitro results on the non-CA neurons of the striatum are indicative of an in vivo role for aFGF and catecholamines in initiating $\mathrm{TH}$ gene expression in CA neurons is not yet known. Certainly, aFGF is found locally in the brainstem (Ferrari et al., 1989; Engele and Bohn, 1991; Fu et al., 1991; Schnürch and Risau; 1991; Wilcox and Unnerstall, 1991; Nurcombe et al., 1993) during the period when CA neurons first differentiate (Specht et al., 1981). However, the presence of other dopamine differentiation factors, such as BDNF, may also prove to be physiologically important for $\mathrm{TH}$ activation during development (Du et al., 1995). Regardless of the growth factor, activation by partner molecules, such as CAs, appears to be a necessary step in $\mathrm{TH}$ gene initiation. The requirement for endogenous CAs, however, poses an obvious paradox for neurons attempting to first initiate CA synthesis. Consequently, biogenic amines must originate extraneuronally if they are to act as aFGF partners during differentiation. One potential internal source of CAs might be cells of the PNS (i.e., sympathetic neurons, adrenal medullary cells) which acquire the capacity to synthesize CAs by E11.5 in the rat (Teitelman et al., 1981), approximately
$1 \mathrm{~d}$ before TH first appears in the CNS (Specht et al., 1981). An alternative source of CAs are those derived externally from the maternal circulation which cross the placenta to freely permeate the embryonic brain (Saunders and Mollgard, 1984; Lossinsky et al., 1986). This putative role for CAs in differentiation is indeed consistent with the widely held view that neurotransmitters mediate many critical functions in fetal development (Coyle, 1972; Lauder, 1988; Mattson, 1988; Meier et al., 1991), including the stimulation of differentiation factor production (Habecker and Landis, 1994). Nonetheless, we can not eliminate the possibility that CAs are not the physiologically relevant partners during development but are merely mimicking their effects by activating signaling pathways in common with those required for TH induction.

The induction of TH elicited by aFGF and dopamine was mechanistically similar to that seen previously with L6 muscle extract (Iacovitti et al., 1989; Iacovitti, 1991), requiring both de novo transcription and translation. However, muscle cells, which manufacture their own aFGF, do not synthesize or take up dopamine or related neurotransmitter compounds. It is, therefore, unlikely that the partner molecule present in L6 cells is one of the CA-containing compounds identified here. Implicit in this conclusion is the existence of multiple activators of aFGF, some found in neurons (i.e., CAs), and at least one other present in muscle. Although the required participation of a partner molecule may be useful for restricting the effects of universal growth substances such as aFGF, the availability of several partners could provide the versatility needed to induce the $\mathrm{TH}$ gene under a variety of different conditions. Conceivably, these different partner molecules might achieve their effects via activation of one or more of the many important transcription binding sites already identified on the TH gene (Lewis and Chikaraishi, 1987; 

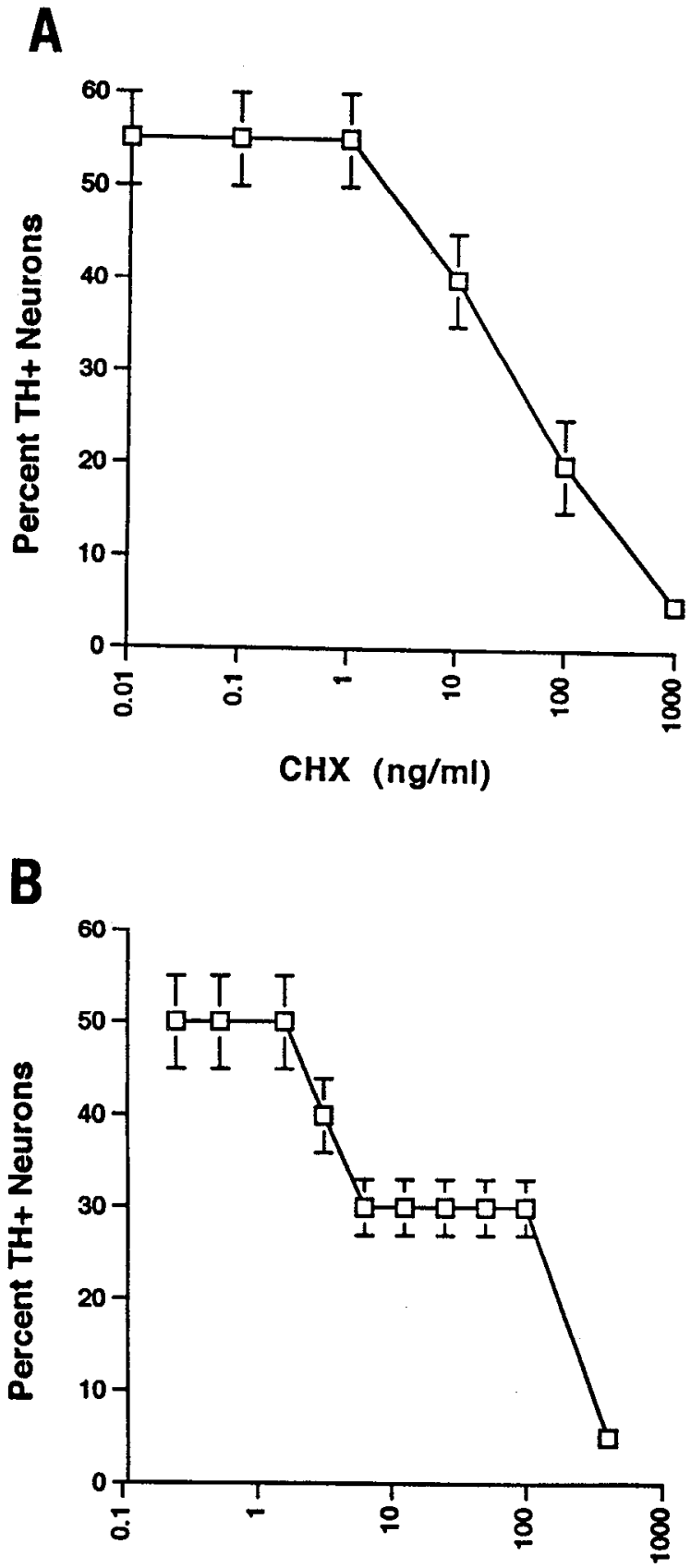

\section{alpha-Amanitin $(\mu \mathrm{g} / \mathrm{ml})$}

Figure 4. Effect of protein and RNA synthesis inhibitors on the TH expression elicited by aFGF and dopamine. Neurons stabilized for $1 \mathrm{~d}$ in culture received $0.01-1000 \mathrm{ng} / \mathrm{ml}$ cyclohexamide $(C H X)$ to inhibit protein synthesis $(A)$ or $0.25-400 \mu \mathrm{g} / \mathrm{ml} \alpha$-amanitin to inhibit RNA polymerases $(B) 2 \mathrm{hr}$ before the addition of $10 \mu \mathrm{M}$ dopamine, $10 \mathrm{ng} /$ $\mathrm{ml}$ aFGF to the culture media. The following day cultures were fixed and stained for $\mathrm{TH}$. Values are expressed as the percentage of $\mathrm{TH}$ positive neurons in the culture. Each value represents the mean \pm SD of four determinations.

Jones et al., 1988; Kemmler et al., 1989; Carroll et al., 1991; Fung et al., 1992; Kim et al., 1993; Murre and Baltimore, 1993). Consistent with this view is the recent finding that tissue specific expression of $\mathrm{TH}$ indeed requires an interaction between two consensus binding sites on the gene (Yoon and Chikaraishi, 1992).

It is not yet clear whether the same substances that first initiate expression of a quiescent $\mathrm{TH}$ gene are also involved in its routine regulation. Although $\mathrm{CA}$ transmitters have long been considered feedback inhibitors of the TH enzyme (Nagatsu et al., 1964; Spector et al., 1967; Weiner et al., 1972; Zigmond et al., 1989), their possible role when combined with the growth factor, aFGF, as feedback inducers of TH has not been explored previously. Thus, as in other systems (Mani et al., 1994), the cross talk between growth factors and neurotransmitters may be essential for proper regulation of $\mathrm{TH}$ at the transcriptional and translational levels.

\section{References}

Adler JE (1989) Neuronal aggregation and neurotransmitter regulation: partial purification and characterization of a membrane-derived factor. Int J Dev Neurosci 7:533-538.

Allen RG (1991) Oxygen-reactive species and antioxidant responses during development: the metabolic paradox of cellular differentiation. Proc Soc Fixp Biol Med 196:117-129.

Black IB (1993) Environmental regulation of brain trophic interactions. Int J Dev Neurosci 11:403-410.

Bonanno G, Raiteri M (1987a) Coexistence of carriers for dopamine and GABA uptake on a same nerve terminal in the rat brain. $\mathrm{Br} \mathrm{J}$ Pharmacol 91:237-243.

Bottenstein JE, Sato GH (1979) Growth of rat neuroblastomid cell line in serum-free supplemented medium. Proc Natl Acad Sci USA 76: $514-517$

Bowers CW (1994) Superfluous neurotransmitters? Trends Neurosci 17:315-320

Carroll JM, Evinger MJ, Goodman HM, Joh TH (1991) Differential and coordinate regulation of TH and PNMT MRNAs in chromaffin cell cultures by second messenger system activation and steroid treatment. J Mol Neurosci 3:75-83.

Cerruti C, Walther DM, Kuhart MJ, Uhl GR (1993) Dopamine transporter mRNA expression is intense in rat midbrain neurons and modest outside midbrain. Mol Brain Res 18:181 186.

Coyle JT (1972) Tyrosine hydroxylase in rat-brain-cofactor requirements, regional and subcellular distribution. Biochem Pharmacol 21: $1935-1944$.

DeVitry F, Hillion J, Catelon J, Thibault J, Benoliel JJ, Hamon M (1991) Dopamine increases the expression of tyrosine hydroxylase and aromatic amino acid decarboxylase in primary cultures of fetal neurons. Dev Brain Res 59:123-131.

Donne CA, Jaye M, Schlessinger J (1991) Structural diversity and binding of FGF receptors. In: Annals of the New York Academy of Sciences, Vol 638, The fibroblast growth factor family (Baird A, Klasbrun M, eds), pp 161-166. New York: New York Academy of Sciences.

Du XY, Stull ND, Iacovitti L (1994) Novel expression of the tyrosine hydroxylase gene requires both acidic fibroblast growth factor and an activator. J Neurosci 14:7688-7694.

Du X, Stull ND, Iacovitti L (1995) Brain-derived neurotrophic factor works coordinately with pariner molecules to initiate tyrosine hydroxylase expression in striatal neurons. Brain Res, in press.

Engele J, Bohn MC (1991) The neurotrophic effects of fibroblast growth factors on dopaminergic neurons in vitro are mediated by mesencephalic glia. J Neurosci 11:3070-3078.

Ferrari G, Minozzi MC, Toffano G, Leon A, Skaper SD (1989) Basic fibroblast growth factor promotes the survival and development of mesencephalic neurons in culture. Dev Biol 133:140-147.

Ferris RM, Tang FI.M, Russell AV (1975) Effects of apomorphine in the uptake and release of catecholamines in crude synaptosomal preparations of rat striatum and hypothalamus. Biochem Pharmacol 24: $1523-1527$.

Foulkes NS, Borrelli S, Sassone-Corsi P (1991) CREM gene: use of alternative DNA-binding domains generates multiple antagonists of cAMP-induced transcription. Cell 64:739-749.

Fu Y-A, Spirito P, Yu Z-X, Biro S, Sasse J, Lei J, Ferrans VJ, Epstein SE, Casscells W (1991) Acidic fibroblast growth factor in the developing rat embryo. Cell Biol 114:1261-1273.

Fung BP, Yoon SO, Chikaraishi DM (1992) Sequences that direct the rat tyrosine hydroxylase gene expression. J Neurochem 58:20442052

Grant S, Revay R, Vaughan R, Freed C, Uhl G, Kuhar MJ (1994) 
Immunohistochemical localization of dopamine transporters in rat brain. Soc Neurosci Abstr 20:920.

Habecker BA, Landis S C (1994) Noradrenergic regulation of cholinergic differentiation. Science 264:1602-1604.

Howard MJ, Gershon MD (1993) Role of growth factors in catecholaminergic expression by neural crest cells: in vitro effects of transforming growth factor beta ${ }_{1}$. Dev Dyn 196:1-10.

Iacovitti L (1991) Effects of a novel differentiation factor on the development of catecholamine traits in noncatecholamine neurons from various regions of the rat brain: studies in tissue culture. J Neurosci $11: 2403-2409$

Iacovitti L (1994) Centrally active differentiation factors in the nervous system. Pharmacol Ther 62:373-383.

Iacovitti L, Evinger MJ, Joh TH, Reis DJ (1989) A muscle-derived factor induces expression of a catecholamine phenotype in cultured rat cerebral cortex. J Neurosci 9:3529-3537.

Iacovitti L, Evinger MJ, Stull ND (1992) Muscle-derived differentiation factor increases expression of the tyrosine hydroxylase gene and enzyme activity in cultured dopamine neurons from the rat midbrain. Mol Brain Res 16:215-222.

Jones NC, Rigby PWJ, Ziff EB (1988) Trans-acting protein factor and the regulation of eukaryotic transcription: lessons from studies on DNA tumor viruses. Genes Dev 2:267-281.

Karin M (1989) Complexities of gene regulation by cAMP. Trends Genet 5:65-67.

Kemmler I, Schreiber E, Muller MM, Matthias P, Schaffner W (1989) Octamer transcription factor bind to two different sequence motifs of the immunoglobulin heavy chain promotor. EMBO J 8:2001-2008.

Kim KT, Park DH, Joh TH (1993) Parallel up-regulation of catecholamine biosynthetic enzymes by dexamethasone in PC12 cells. J Neurochem 60:946-951.

Lamb P, McKnight SL (1991) Diversity and specificity in transcriptional regulation: the benefits of heterotypic dinerization. Trends Biochem 16:417-427.

Lauder J (1988) Neurotransmitters as morphogens. Prog Brain Res 73: $365-387$.

Lewis EJ, Chickaraishi DM (1987) Regulated expression of the tyrosine hydroxylase gene by epidermal growth factor. Mol Cell Biol 7:3332-3336.

Lossinsky AS, Vorbrodt AW, Wisniewski HM (1986) Characterization of endothelial cell transport in the developing mouse blood-brain barrier. Dev Neurosci 8:61-75.

Louis J-C, Magal E, Burnham P, Varon S (1993) Cooperative effects of ciliary neurotrophic factor and norepinephrine on tyrosine hydroxylase expression in cultured rat locus coeruleus neurons. Dev Biol 155:1-13.

Magal E, Burnham P, Varon S, Louis J-C (1993) Convergent regulation by ciliary neurotrophic factor and dopamine of tyrosine hydroxylase expression in cultures of rat substantia nigra. Neuroscience 52:867881

Mani SK, Allen JMC, Clark JH, Blaustein JD, O'Malley BW (1994) Convergent pathways for steroid hormone- and neurotransmitter-induced rat sexual behavior. Science 265:1246-1249.

Mattson M (1988) Neurotransmitters in the regulation of neuronal cytoarchitecture. Brain Res Rev 13:179-212.

Maus MP, Bertrand S, Drouva R, Rasolonjanahary C, Kordon J, Glowinski J, Premont J, Enjalbert A (1989) Differential modulation of D and $\mathrm{D}_{2}$ dopamine-sensitive adenylate cyclases by $17 \beta$-estradiol in cultured striatal neurons and anterior pituitary cells. J Neurochem 52 410-418.

McElvain JS, Schenk JO (1992) A multisubstrate mechanism of striatal dopamine uptake and its inhibition by cocaine. Biochem Pharmacol 434:2189-2199.

Meier E, Hertz L, Schousboe A (1991) Neurotransmitters as developmental signals. Neurochem Int 19:1-15.

Meiergerd SM, Schenk JO (1994) Striatal transporter for dopamine: catechol structure-activity studies and susceptibility to chemical modification. J Neurochem 62:998-1008.

Murre C, McCaw PS, Baltimore D (1989) A new DNA binding and dimerization motif in immunoglobulin enhancer binding, daughterless MyoD, and myc proteins. Cell 56:777-783.

Nagatsu T, Levitt M, Udenfriend S (1964) Tyrosine hydroxylase: the initial step in norepinephrine biosynthesis. J Biol Chem 239:29102917.
Nurcombe V, Ford MD, Wildschut JA, Barlett PF (1993) Development regulation of neural response to FGF-1 and FGF-2 by heparan sulfate proteoglycan. Science 260:103-106.

Premont J, Dauguet-de Montety M-C, Herbet A, Glowinski J, Bockaert J, Prochiantz A (1983) Biogenic amines and adenosine-sensitive adenylate cyclases in primary cultures of striatal neurons. Brain Res 285:53-61.

Radian R, Ottersen OP, Storm-Mathisen J, Castel M, Kanner BI (1990) Immunocytochemical localization of the GABA transporter in rat brain. J Neurosci 10:1319-1330.

Rao MS, Landis SC (1993) Cell interactions that determine sympathetic neuron transmitter phenotype and the neurokines that mediate them. J Neurobiol 24:215-232.

Roeder RG (1976) Eukaryotic nuclear RNA polymerases. In: RNA polymerase (Losick R, Chamberlin M, eds), pp 285-329. Cold Spring Harbor, NY: Cold Spring Harbor Laboratory.

Rohrer H (1992) Cholinergic neuronal differentiation factors: evidence for the presence of both CNTF-like and non-CNTF-like factors in developing rat footpad. Development 114:689-698.

Saadat S, Thoenen H (1986) Selective induction of tyrosine hydroxylase by cell-cell contact bovine adrenal chromaffin cells is mimicked by plasma membranes. J Cell Biol 103:1991-1997.

Saunders NR, Møllgård K (1984) Development of the blood-brain barrier. J Dev Physiol 6:45-57.

Schnürch H, Risau W (1991) Differentiating and mature neurons express the acidic fibroblast growth factor gene during chick neural development. Development 111:1143-1154.

Shimada S, Kitayama S, Lin C-L, Patel A, Nanthakumar E, Gregor P, Kuhar M, Uhl G (1991) Cloning and expression of a cocaine-sensitive dopamine transporter complementary cDNA. Science 254:576577

Shimada S, Kitayama S, Walther D, Uhl G (1992) Dopamine transporter mRNA: dense expression in ventral midbrain neurons. Mol Brain Res 13:359-362.

Specht LA, Pickel VM, Joh TH, Reis DJ (1981) Light microscopic immunocytochemical localization of tyrosine hydroxylase in prenatal rat brain. I. Early ontogeny. J Comp Neurol 199:233-253.

Spector S, Gordon R, Sjoerdsma A, Udenfriend S (1967) End-product inhibition of tyrosine hydroxylase as a possible mechanism for regulation of norepinephrine synthesis. Mol Pharmacol 3:549-555.

Stott D (1991) Analysis of transcriptional initiation in isolated nuclei. In: Methods in molecular biology, Vol 7, Gene transfer and expression protocols (Murray EJ, ed), pp 327-335. Clifton, NJ: Humana.

Teitelman G, Baker H, Joh TH, Reis DJ (1979) Appearance of catecholamine synthesizing enzymes during development of rat sympathetic nervous system: possible role of tissue environment. Proc Natl Acad Sci USA 76:509-513.

Uhl GR (1992) Neurotransporters (plus): a promising new gene family Trends Neurosci 15:265-268.

Van Vliet BJ, Ruuls SR, Drukarch B, Mulder AII, Schloffelmeer ANM (1991) $\beta$-Adrenoceptor-sensitive adenylate cyclase is inhibited by activation of $\mu$-opioid receptors inn the rat striatum. Eur J Pharmacol 195:295-300

Weiner N, Cloutier G, Bjur R, Pfeffer RI (1972) Modification of norepinephrine synthesis in intact tissue by drugs and during short-term adrenergic nerve stimulation. Pharmacol Rev 24:203-221.

Weiss S, Kemp DE, Lenox RH, Ellis J (1987) $\alpha_{2}$-Adrenergic receptors mediate inhibition of cyclic AMP production in neurons in primary culture. Brain Res 414:390-394.

Wilcox B, Unnerstall J (1991) Expression of acidic fibroblast growth factor mRNA in the developing and adult rat brain. Neuron 6:397409

Wong V, Kessler JA (1987) Solubilization of a membrane factor that stimulates levels of substance $P$ and choline acetyltransferase in sympathetic neurons. Proc Natl Acad Sci USA 84:8726-8729.

Yamamori T, Fukada K, Aebersold R, Korsching S, Fann MJ, Patterson PH (1989) The cholinergic neuronal differentiation factor from heart cells is identical to leukemia inhibitory factor. Science 246:14121416.

Yoon SO, Chikaraishi DM (1992) Tissue-specific transcription of the rat tyrosine hydroxylase gene requires synergy between and AP-1 motif and an overlapping $E$ box-containing dyad. Neuron 9:55-67.

Zigmond RE, Schwarzschild MA, Rittenhouse AR (1989) Acute regulation of tyrosine hydroxylase by nerve activity and by neurotransmitters via phosphorylation. Annu Rev Neurosci 12:415-461. 